\title{
Differential response of human fetal smooth muscle cells from arterial duct to retinoid acid ${ }^{1}$
}

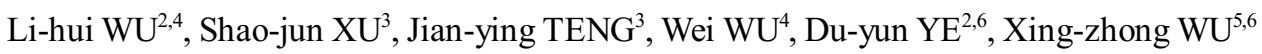 \\ ${ }^{2}$ Department of Pathophysiology, Tongji Medical College of Huazhong, University of Science and Technology, Wuhan 430030, China; ${ }^{3}$ Department of \\ Surgery, Medical College of Hangzhou Normal College, Hangzou 310018, China; ${ }^{4}$ Department of Children's Development and Behavior, Yuying \\ Children's Hospital of Wenzhou Medical College, Wenzhou 325003, China; ${ }^{5}$ Department of Biochemistry, Shanghai Medical College, Fudan University, \\ Shanghai 200032, China
}

\section{Key words}

isolated patent ductus arteriosus; vascular smooth muscle cells; retinoic acid

${ }^{1}$ This work was supported by grants from Wen Zhou Scientific and Technological Bureau (No H2006023), the National Natural Science Foundation of China (№ 30570414 and 30470398), and the Zhejiang Medical Foundation for young scientists (No_2005QNo16).

${ }^{6}$ Correspondence to Dr Xing-zhong WU and Dr Du-yun YE.

Phn/Fax 86-21-5423-7697.

E-mail xz_wu@shmu.edu.cn (Xing-zhong WU)

Phn 86-27-8365-0562.

E-mailyedy@mails.tjmu.edu.cn (Du-yun YE)

Received 2007-09-12

Accepted 2007-11-19

doi: 10.1111/j.1745-7254.2008.00766.x

\begin{abstract}
Aim: The aim of the present study was to understand the role of retinoic acid (RA) in the development of isolated patent ductus arteriosus and the features of arterial duct-derived vascular smooth muscle cells (VSMC). Methods: The VSMC were isolated, and the biological characteristics and the response to RA were investigated in the arterial duct, aorta, and pulmonary artery VSMC from 6 human embryonic samples. Western blotting, immunostaining, and cell-based ELISA were employed to analyze the proliferation regulation of VSMC. Results: The VSMC from the arterial duct expressed proliferating cell nuclear antigen (PCNA) at a significantly lower rate than those from the aorta and pulmonary artery, but expressed a higher level of Bax and Bcl-2. The expression level of PCNA or Bcl-2 was associated with the embryonic age. The effects of RA on the VSMC from the arterial duct were quite different from those from the aorta and pulmonary artery. In arterial duct VSMC, RA stimulated PCNA expression, but such stimulation could be suppressed by CD2366, an antagonist of nuclear retinoid receptor activation. In aorta or pulmonary artery VSMC, the expression response of PCNA to RA was insignificant. The ratio of Bax/Bcl-2 decreased in arterial duct VSMC after RA treatment due to the significant inhibition of Bax expression. Conclusion: The VSMC from the arterial duct possessed distinct biological behaviors. RA might be important in the development of ductus arteriosus VSMC.
\end{abstract}

\section{Introduction}

Smooth muscle cells (SMC) play a very important role in the development of the cardiovascular system in human fetuses. The arterial duct, which connects the systemic and pulmonary circulations, is derived from the aortic arch and normally extends from the main or left pulmonary artery to the descending aorta just distal to the origin of the left subclavian artery. The ductus is usually $5-10 \mathrm{~mm}$ long before birth, exhibiting some length variability, and the diameter varies from a few millimeters to $1-2 \mathrm{~cm}$. Closure of the ductus occurs at or after birth during the transition from fetal to postnatal circulation. Isolated patent ductus arteriosus (PDA) occurs approximately once in every 2500-5000 live births. The incidence of PDA is related to several factors, including decreased smooth muscle content in the ductal wall, diminished responsiveness of the ductal smooth muscle to oxygen, and possibly other factors. Postnatal ductus constriction produces hypoxia of the inner vessel wall, which might lead to cell death and the release of some hypoxiainducible growth factors that stimulate endothelial proliferation. Permanent closure of the ductus arteriosus requires loss of cells from the muscle media through the programmed cell death pathway and the development of neointimal mounds by proliferation of endothelial cells ${ }^{[1]}$. Thus, failure in the constriction of the postnatal arterial ductus could be the key factor for the event of PDA. Some 
pathways are considered to be associated with controlling cell apoptosis and proliferation. Apoptosis is regulated by proteins of the Bcl-2 family consisting of both anti-apoptotic and pro-apoptotic factors. Bax regulates apoptosis ${ }^{[2]}$ by binding to Bcl-2, and the Bax expression level over Bcl-2 is thus considered an indicator for cell apoptosis or growth. Mitogen activated protein kinases (MAPK) regulate cell growth and apoptosis, and much attention has focused in recent years on 3 subfamilies of MAPK: the extracellular signalregulated kinases (ERK), c-Jun N-terminal kinases (JNK), and the $\mathrm{p} 38 \mathrm{MAPK}^{[3]}$. These enzymes are regulated by a characteristic phosphorylation system in which a series of 3 protein kinases phosphorylate and activate one another ${ }^{[4]}$. The ERK function controls cell division, and the inhibition of these enzymes is generally considered antiproliferative in certain cells ${ }^{[5,6]}$. The JNK are critical regulators of transcription, and JNK inhibitors may contribute to apoptosis resistance.

Retinoic acid (RA), an oxidative metabolite of vitamin A, regulates many biological processes, including embryonic development and cell differentiation ${ }^{[7-9]}$. Vitamin A is considered an important factor for heart development. There are suggestions that there is a link between vitamin A and $\mathrm{PDA}^{[10]}$, and RA has been shown to be important in the development of the fetal ductus arteriosus ${ }^{[11]}$. In this study, we investigated whether human fetal SMC from the aorta, pulmonary artery, and arterial duct tissues possess different biological behaviors, vulnerabilities to teratogenic insults, and distinct response to RA. We investigated the RA receptor antagonist influence on the effect of RA.

\section{Materials and methods}

Samples A total of 8 human fetal embryonic samples were obtained from Wenzhou Medical College (Wenzhou, China) under Chinese law statutes. The tissue collection used in the current research was obtained with the approval of the local Human Ethics Committee (Wenzhou Medical College, China), and our procedures were in compliance with the Helsinki Declaration on human experimentation. All specimens were obtained from voluntary pregnancy terminations due to personal reasons other than health problems, was and were induced by mifepristone and prostaglandins; written informed consent was obtained from all donors. The gestational periods varied from 18-22 weeks of development with an average $18 \pm 2$ weeks. The embryonic age was determined by measuring the head diameter and crown-rump length based on the data published by Forutan et $a l^{[12]}$ and calculated according to the time from the last menstrual period (LMP) under the assumption that fertilization occurs $14 \mathrm{~d}$ after the LMP. No abnormal data were found in the obstetrical examination of the conceived women and the B-supersonics examination of the fetus before the operation.

Main reagents Dulbecco's modified Eagle's medium (DMEM) and fetal bovine serum (FBS) were from Gibco BRL (Carlsbad, CA, USA). The immunohistochemistry SP kit was from Zymed (South San Francisco, CA, USA). Proliferating cell nuclear antigen (PCNA), antihuman $\alpha$-actin (smooth muscle), and antihuman Bax monoclonal antibody were from Neomarkers (Fremont, CA, USA). Antihuman Bcl-2 monoclonal antibodies were from Zymed (USA). Fast-activated, cell-based extracellular (FACE) signal-regulated kinases $1 / 2$ and JNK ELISA kits were from Activemotif (Carlsbad, CA, USA). RA was from SigmaAldrich (St Louis, MO, USA). CD2366 was kindly provided by R\&D (Sophia, Antipolis, France). The enhanced chemiluminescent (ECL) horseradish peroxidase (HRP) substrate was from Millipore (Billerica, CA, USA).

Primary tissue culture After the pregnancy terminations, the fetus samples were immediately kept on ice under asepsis condition. Within $2 \mathrm{~h}$ after the operation, the fetal heart, aorta, and pulmonary artery were dissected. Primary fetal SMC (VSMC) from the aorta, pulmonary artery, and arterial ductus were cultured within $24 \mathrm{~h}$ after induction of cervical dilation by the modified explant-attached method ${ }^{[13]}$. Briefly, under a microscope, the aorta, pulmonary artery, and arterial ductus were isolated. All the vessels were vertically cut and the intimal epithelium tissue was scrapped by a scalpel. Then the vessels were washed by cool DMEM culture medium and cut into $0.5-1 \mathrm{~mm}^{3}$ pieces. The pieces were covered and pressed with glass slides in $60 \mathrm{~mm}$ diameter culture dishes and maintained in DMEM containing $20 \% \mathrm{FBS}$ at $37^{\circ} \mathrm{C}$ with $5 \% \mathrm{CO}_{2}$ so that cells could grow on the surface of both the dish bottom and cover glass. The double surface enabled the cells to grow well on both sides within a short period. Half the medium was replaced with fresh DMEM containing $20 \%$ FBS 3 times a week until the cells were confluent around the tissue pieces. The cells on the glass slides were used for the staining of SMC, and the cells in the dishes were continuously cultured.

RA induction Fetal SMC from the aorta, pulmonary artery, and arterial duct tissues from fewer than 5 passages were prepared on glass slides. When the cells adhered onto the slides, all slides were placed in fresh DMEM containing 20\% FBS. $0.5 \mu \mathrm{mol} / \mathrm{L}$ RA was added to the RA group, $0.5 \mu \mathrm{mol} / \mathrm{L}$ CD2366 was added to the CD group, and 0.5 imol/L RA and CD2366 was added to the RA+CD group. The medium con- 
taining the same volume of ethanol was set as the control group. All cells were incubated for $24 \mathrm{~h}$ and removed from the medium for the observation of PCNA, Bax, and Bcl-2 protein expressions. All of the experiments were repeated at least 5 times.

Immunohistochemistry Immunohistochemistry was performed according to the manufacturer's protocol of the immunohistochemistry SP kit. Briefly, PCNA, Bax, and Bcl-2 antibody concentrations were $1: 100,1: 100$, and 1:100, respectively. The $\alpha$-actin antibody specific for SMC was diluted at 1:200. HRP-conjugated goat antimouse immunoglobulin was used as the secondary antibody and worked at $1: 1000$. Mouse immunoglobulins replaced the first antibodies on the negative control slides. The samples were visualized by diaminobenzidine tetrahydrochloride, the HRP substrate, and observed under an Olympus light microscope (Tokyo, Japan). Positive staining was shown as brown or yellow. The staining intensity of the color was classified into 3 grades: dark brown $(+++)$, light brown $(++)$, and yellow $(+)$. The positive signal of each case was quantified as the number of cells with $+++\times 3,++\times 2$, and $+\times 1$, as determined by weighing. On each slide, $200 \mathrm{SMC}$ were randomly chosen, observed, and counted for the positive staining percentage.

Western blotting The cells were washed twice with phosphate-buffered saline (PBS) and lysed in buffer consisting of $50 \mathrm{mmol} / \mathrm{L} \mathrm{Tris-HCl}(\mathrm{pH} 8.0), 0.5 \%(v / v)$ Tween $20,1 \mathrm{mmol} / \mathrm{L}$ EDTA, $2 \mathrm{mmol} / \mathrm{L}$ phenylmethylsulfonyl fluoride, and $1 \mu \mathrm{g} / \mathrm{mL}$ aprotinin. The proteins were assayed by the Bradford method and mixed equally with $2 \times$ SDS loading buffer and resolved on SDS-PAGE gel. The proteins on the gel were then transferred onto a polyvinylidene difluoride membrane (Millipore, Bedford, MA, USA). After blocking with 5\% milk protein in PBST (PBS containing $0.05 \%$ Tween 20) for $2 \mathrm{~h}$ at room temperature, the membranes were incubated with specific primary antibodies for $6 \mathrm{~h}$ at $4{ }^{\circ} \mathrm{C}$. Then the blots were washed 3 times with PBST and incubated for $2 \mathrm{~h}$ with HRP-conjugated secondary antibodies. Immunolabeling was detected by ECL after washing with PBST. All experiments were repeated at least 3 times independently.

Flow cytometric analysis The flow cytometric analysis method was according to our previous study ${ }^{[9]}$. The cells were collected and washed 3 times with $10 \mathrm{~mL}$ PBS (pH 7.4) after culture. Then the cell pellets were added with $1 \mathrm{~mL}$ hypotonic solution $(50 \mu \mathrm{g} / \mathrm{mL}$ propidium iodide, $0.1 \%$ sodium citrate, and $0.1 \%$ triton $\mathrm{X}-100$ ) at $4{ }^{\circ} \mathrm{C}$ overnight. Then 20000 cells were acquired and detected in the FACS (Becton Dickinson Biosciences, Mountein View, CA, USA) machine by Cell Quest software (Becton Dickinson Biosciences, Mountein View, CA, USA). The data of the cell cycle were analyzed by Mod Fit LT version 2.0 software fitting the apoptosis mode.

FACE ELISA The FACE signal-regulated kinase measurement was according to the protocol provided by the manufacturer (Activemotif, USA). Briefly, for the detection of activated (phospho-) ERK1/2 and JNK in different media, the cultured primary aorta, pulmonary artery, and arterial duct cells from fewer than 5 passages were prepared in $5 \times 10^{5}$ cells $/ \mathrm{mL}$, respectively, and $100 \mu \mathrm{L}$ cell suspension was added to each well of the 96-well plate. After all of the cells had been incubated for $48 \mathrm{~h}$ and adhered to the bottom of the wells, $100 \mu \mathrm{L}$ cultured media containing 20\% FBS (as the control group), $0.5 \mu \mathrm{mol} / \mathrm{L}$ RA, $0.5 \mu \mathrm{mol} / \mathrm{L}$ CD2366, and $0.5 \mu \mathrm{mol} / \mathrm{L}$ $\mathrm{RA}+\mathrm{CD} 2366$ were added to the wells as 4 groups, respectively, replacing the original media. After treatment, the cells in the 96-well plate were fixed with $100 \mu \mathrm{L}$ of $4 \%$ formaldehyde in PBS. Relative phospho-ERK1/2 and phospho-JNK levels were detected with a cell-based ELISA kit. The phospho-ERK1/2 and phospho-JNK antibodies were applied into the well at concentrations of $1: 250$ and 1:125, respectively. PBS replaced the antibodies in the negative control wells. After incubation, the addition of the secondary antibody, and washing, chromogen was added. After development, the absorbance of each well was read on a spectrophotometer within $5 \mathrm{~min}$ at a wavelength of $450 \mathrm{~nm}$ over $655 \mathrm{~nm}$, which indicated the expression level of phospho-ERK1/2 and phospho-JNK. Meanwhile, the absorbance of each well was also read at $595 \mathrm{~nm}$ after crystal violet staining, which indicated the cell numbers in each well. The absorbance values at $450 \mathrm{~nm}$ were normalized according to the absorbance value at $595 \mathrm{~nm}$.

Statistics The data in the study were presented as mean \pm SD for each group. ANOVA and the SNK(StudentNewman-Keuls) test were used for the variance analysis among the test groups. Comparisons between 2 groups were analyzed by Student's $t$-test.

\section{Results}

Characteristics of the fetal SMC After 3-5 d of primary culture, the cells were observed growing from the edges around the tissues and in emitting order. After a 2 week incubation period, many long, spindle-like cells were observed. The third passage cells from the tissues were prepared for staining with the monoclonal antibody against $\alpha$-actin, which is specific for SMC. The results found that $97 \%$ of the cells were stained positive, and the control showed negative staining by mouse immunoglobulins (Figure 1A). The cells from the aorta, pulmonary artery, and arterial 
A

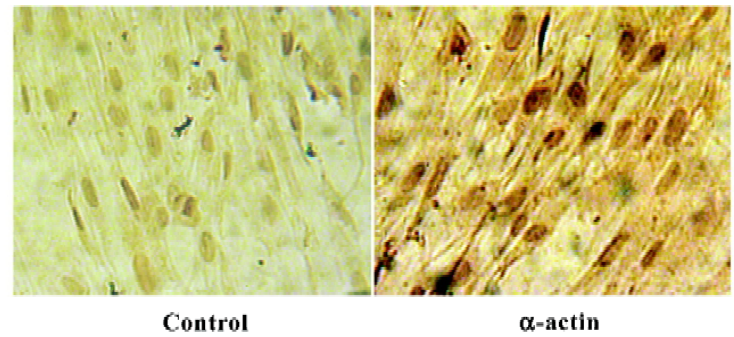

B
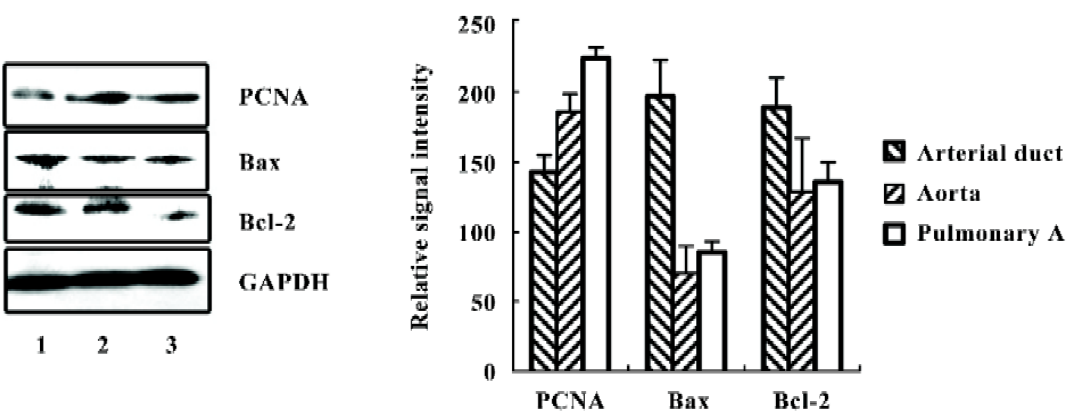

C
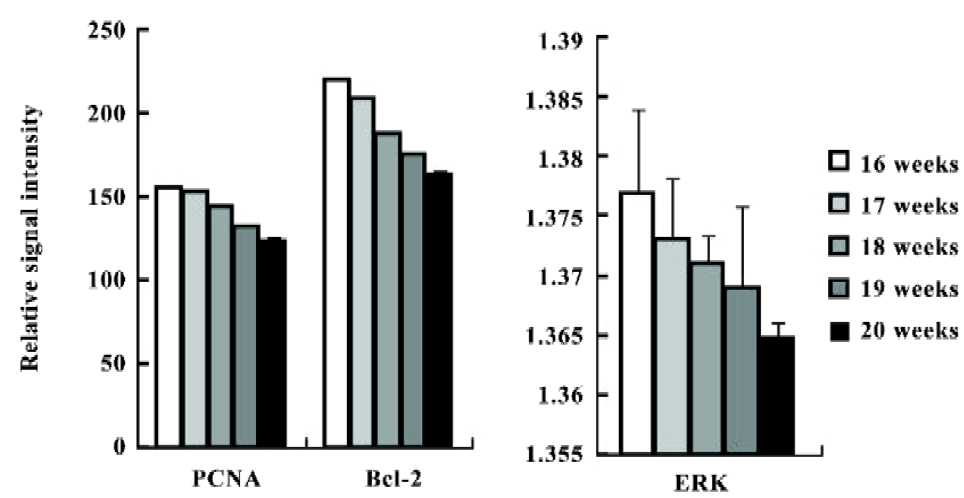

Figure 1. Characteristics of the fetal arterial duct SMC. (A) primarily cultured cells from arterial duct were shown as SMC by positive staining with the $\alpha$-actin monoclonal antibody specific for SMC. No positive signals were found in the negative control with mouse immunoglobulins. (B) Expression level comparison of PCNA, Bax, and Bcl-2 among the SMC from the arterial duct, aorta, and pulmonary artery. The right panel shows the mean $\pm \mathrm{SD}$ of the relative signal intensities in immunostaining of 6 cases of the aorta, pulmonary artery, and arterial duct. Data were subjected to ANOVA for the comparisons. Left panel shows the results of Western blotting in which lanes 1-3 represent the arterial duct, pulmonary artery, and aorta VSMC, respectively. (C) expression level comparison of PCNA, Bcl-2, and ERK in arterial SMC during embryonic development.

ductus tissues were all 95\%-97\% positive with $\alpha$-actin. We also tested this antibody with a 39 week embryonic lung tissue and did not find it to stain (data not shown). This suggested the cultured cells were fetal SMC.

Next, we examined the expression of PCNA on fetal SMC from these 3 tissue sources by immunostaining and Western blotting. The results shown in Figure 1B suggest that the cells from the arterial ductus expressed the lowest level of PCNA among the 3 groups in 6 cases. There was a significant variance among the 3 groups $(P<0.01)$. Bax/Bcl-2 was consid- ered as a switch for controlling cell growth or apoptosis ${ }^{[14,15]}$. In these 3 kinds of primary cells, the SMC from the arterial ductus were found to have the highest expressional ratio of $\mathrm{Bax} / \mathrm{Bcl}-2$ (1.04:1). In the aorta and pulmonary artery SMC, the $\mathrm{Bax} / \mathrm{Bcl}-2$ ratio was $0.55: 1$ and $0.629: 1$, respectively. Interestingly, we also observed that the expression levels of PCNA and Bcl-2 were related to fetal age. As the embryos grew, the arterial duct SMC expressed less PCNA and Bcl-2 (Figure 1C). The value for ERK was also found to decrease with age. 
Response to RA We further observed the response of these primary SMC to RA exposure. Interestingly, RA did not suppress arterial duct SMC growth, but stimulated the cells to express PCNA. In the control cells, the relative signal intensity for PCNA was $142.67 \pm 12.08$. After RA treatment, the signal intensity was enhanced to $175.33 \pm 10.80(P<0.05$, $n=6$; Figure 2A,2B,2G). Together with CD2366, a RA receptor-selective antagonist ${ }^{[16]}$, the induction of PCNA by RA expression was overcome. There were no differences of the PCNA expression levels among the control, $\mathrm{CD}$ and RA+CD groups. The treatment with only CD2366 failed to enhance PCNA expression. In the aorta or pulmonary artery SMC, RA treatment did not induce any significant change of PCNA expression.

In contrast, RA treatment significantly inhibited Bax expression (Figure 2C,2D,2G) in the arterial duct SMC, and the relative signal intensity decreased to $100.00 \pm 12.31$ from $196.71 \pm 25.79$ in the control $(P<0.01, n=6)$. Such inhibition of Bax expression could not be overcome by adding CD2366 because CD2366 itself reduced Bax expression. However, Bcl-2 expression after RA treatment as reduced slightly from the control $189.33 \pm 21.13$ to $162.83 \pm 20.2$. Therefore, the ratio of Bax/Bcl-2 increased to 1.21:1 from 1.04:1, which suggested that RA stimulated proliferation in the primary fetal arterial duct SMC. In the aorta and pulmonary artery SMC, RA treatment did not significantly increase the ratio of Bax/Bcl-2 (Figure 2E,2F,2G). In this study, treatment with $0.5 \mu \mathrm{mol} / \mathrm{L}$ RA for $24 \mathrm{~h}$ did not cause any significant apoptosis peak in the flow cytometric analysis.

Activation of ERK1/2 and JNK ERK can be activated by phosphorylation of the molecule. The phospho-ERK was thus considered the activated form. Therefore, we further
A

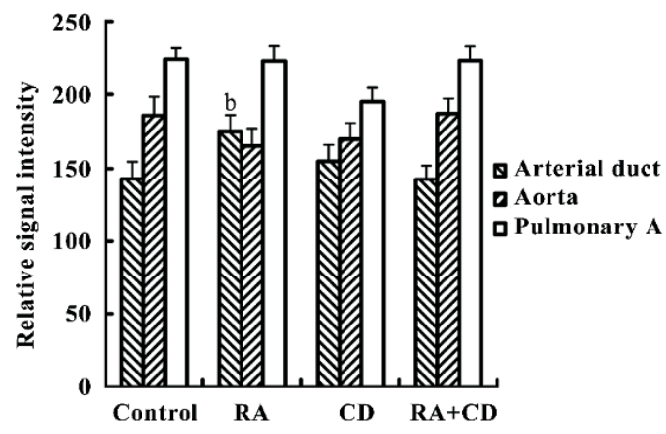

B

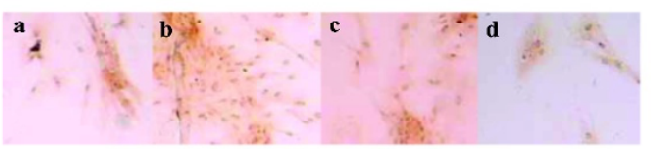

C

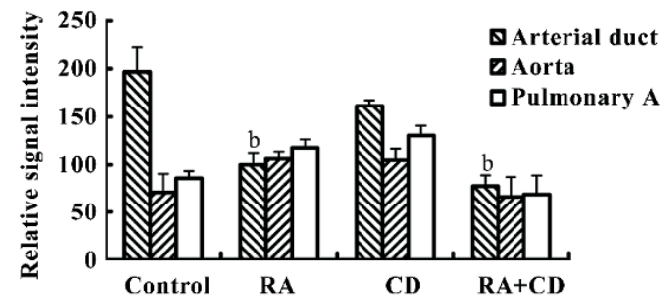

D

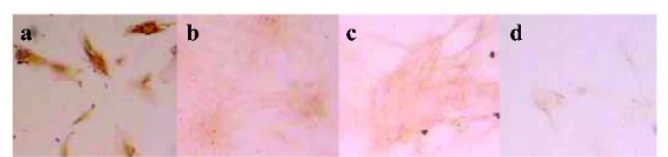

E

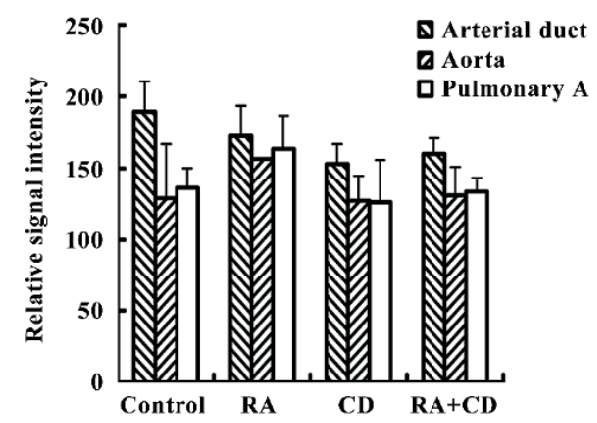

F

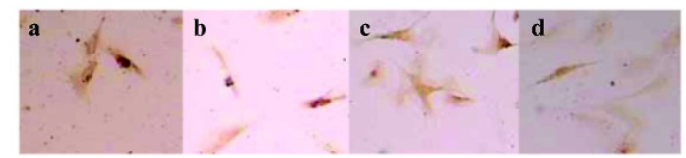

G

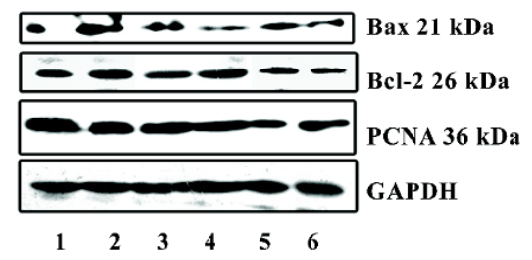

Figure 2. Fetal SMC response to RA. Primary SMC were incubated with $0.5 \mu \mathrm{mol} / \mathrm{L}$ RA, $0.5 \mu \mathrm{mol} / \mathrm{L}$ CD2366, or RA+CD2366. Control group (A) contained the same volume of ethanol. Cellular PCNA (A,B), Bax (C,D), and Bcl-2 (E,F) antibodies were stained, and the relative signal intensity was obtained after examination of the slides (B,D,F). Immunoblotting was performed at the same time and similar results were achieved (G). Experiments were repeated at least 3 times, and 1 representative is shown. Lanes 1 and 2 represent the RA-treated and control groups of the arterial duct. Lanes 3 and 4 represent the RA-treated and control groups of the pulmonary artery. Lanes 5 and 6 represent the RA-treated and control groups of the aorta. ${ }^{\mathrm{b}} P<0.05$. 
investigated the expression levels of phospho-ERK1/2 and phospho-JNK after RA stimulation. Using the FACE ELISA assay, the absorbance values obtained from the fetal smooth muscle aorta, pulmonary artery, and arterial duct cells are summarized in Figure 3A. The fetal arterial duct SMC expressed the lowest level of phospho-ERK1/2 among these 3 cells. However, it increased significantly to $1.609 \pm 0.040$ from $1.370 \pm 0.005$ (absorbance: $450 \mathrm{~nm}, P<0.05, n=6$ ). This action could not be cancelled by CD2366. The changes in the pulmonary artery SMC did not reach significance after RA treatment (Figure 3A).

The phospho-JNK was expressed differently. The SMC from the arterial duct had the highest level of $0.371 \pm 0.006$, but the aorta had the level of $0.229 \pm 0.005$ and the pulmonary artery $0.239 \pm 0.006$ (Figure 3B). After RA treatment, the expression level in the arterial duct declined to $0.326 \pm 0.007$ from $0.371 \pm 0.006(P<0.05, n=6)$. Such an inhibition of phospho-JNK expression could not be overcome by CD2366.

A

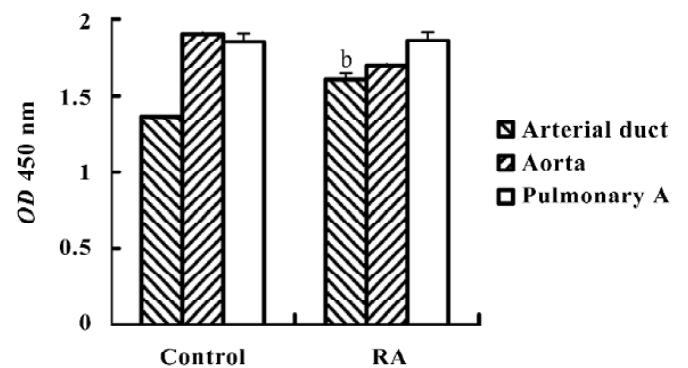

B

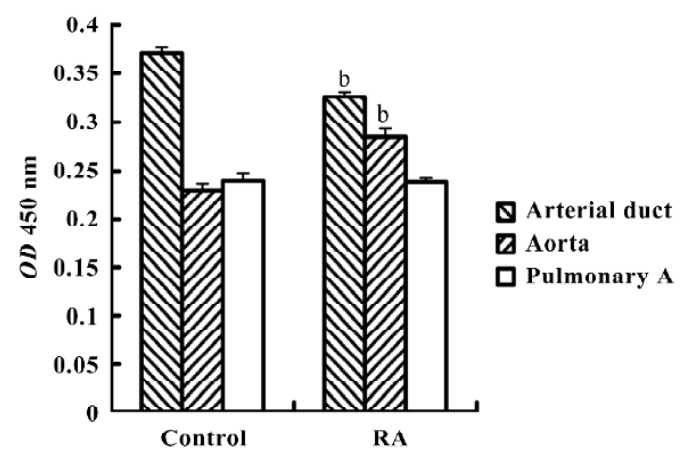

Figure 3. Activation of ERK and JNK. SMC were seeded into the 96-well plate and treated with $0.5 \mu \mathrm{mol} / \mathrm{L} \mathrm{RA}, 0.5 \mu \mathrm{mol} / \mathrm{L} \mathrm{CD} 2366$, or $\mathrm{RA}+\mathrm{CD} 2366$. Then the cells were incubated with the specific antibody against phospho-ERK1/2 (A) or phospho-JNK (B). After incubation with the secondary antibody and color development, data were expressed as absorbance value at $450 \mathrm{~nm}$, which were further averaged from 6 cases with SD. ${ }^{b} P<0.05$.

\section{Discussion}

The PDA often causes abnormal circulation of the blood and harms children's health. Hypoxia may be involved in this disease. If there are anatomic changes of the PDA in adult patients, such as aortic aneurysm, calcification, or being short and sometimes friable can further complicate surgical treatment ${ }^{[17]}$. The closure of the arterial duct depends on the smooth muscle contraction. Mutations in the MYH11 gene affecting the $\mathrm{C}$-terminal coiled-coil region of the smooth muscle myosin heavy chain, a contractile protein of SMC, could cause the disease ${ }^{[18]}$. The SMC appear to be different in the arterial duct from other VSMC from the aorta and pulmonary artery in our results. PCNA, which functions in DNA replication and cellular proliferation processes, is expressed significantly lower, while Bax and Bcl-2 are much higher in arterial duct VSMC than those in aorta and pulmonary artery. The protein of Bcl-2 is related to apoptosis and its activity is regulated by a related $21 \mathrm{kDa}$ protein known as Bax. An increase in the ratio of Bax to Bcl-2 can lead to cell growth inhibition and apoptosis ${ }^{[19]}$. A lower expression of PCNA and higher expression of Bax indicate that arterial duct VSMC grow in a slower rate than those from the aorta and pulmonary artery.

Interestingly, RA stimulated the growth of arterial duct VSMC, but not of aorta and pulmonary artery VSMC. After arterial duct SMC exposure to RA, these cells proliferated, as evidenced by the stimulation of PCNA expression and the decreased $\mathrm{Bax} / \mathrm{Bcl}-2$ ratio. The proliferation-stimulated effects of RA on the cells tested herein were generally reduced by the co-administration of CD2366, an RAR(RA receptor)selective antagonist, which is an adamantyl-methoxyphenylheptatrienoic acid derivative ${ }^{[20]}$. This suggested that RA stimulation of proliferation in the arterial duct was through the RAR activation pathway. However, it was not clear whether the regulation of Bax expression by RA was through its receptors or not because CD2366 itself affects Bax expression in the system. Additionally, in the arterial duct SMC, high levels of phosphorylated ERK1/2 and low levels of phosphorylated JNK were also noted. These results demonstrated that RA induced proliferation in arterial duct-derived VSMC, but not in aorta or pulmonary artery-derived VSMC. Our results are consistent with a recent publication in which the authors demonstrate that RA stimulates the response of SMC in the ductus arteriosus to platelet-derived growth factor and promote intimal cushion formation ${ }^{[21]}$. Retinoid exposure during gestation can induce developmental defects if administered before neurulation; however, if given after neurulation, it is not so teratogenic ${ }^{[22]}$. Exposure to idarubicin and RA early in the second trimester of pregnancy causes transient dilated cardiomyopathy in a term newborn $^{[23]}$. However, some published studies have sug- 
gested that vitamin A is important in the development of the fetal ductus arteriosus ${ }^{[24,25]}$. Maternal administration of RA may accelerate the mature process in the fetal ductus arteriosus and the development of the $\mathrm{O}_{2}$-sensing mechanism of the ductus arteriosus ${ }^{[26]}$. We did not know the RA level in the fetus blood because the blood was already clotted in our fetus samples and therefore, could not be used for the measurement. The content in the cultured VSMC was too low to be detected by using high-pressure liquid chromatography. However, evidence showed that endogenous RA signaling is often colocalized with the expression of the adult smooth muscle myosin heavy chain isoform during ductus arteriosus development ${ }^{[27]}$, which leads to the closure of the ductus arteriosus. There is no evidence showing prostaglandins specifically affect embryonic ducts rather than the aorta or pulmonary artery, although prostaglandins were used to induce the abortions.

The incidence of PDA has been associated with a decreased mass of smooth muscles in the ductal wall, and RA can induce proliferation of ductal SMC. Our findings suggest that adequate RA may be useful for preventing PDA. Conversely, excessive RA in the embryo can cause aortic SMC to undergo apoptosis, such that an RA overdose may lead to developmental defects of the aorta. Thus, improper (either excessive or deficient) levels of retinoids may induce teratogenesis during the development of the cardiovascular system structures, such as the aorta, pulmonary artery, and arterial duct.

We also observed changes in the arterial duct VSMC from the embryos aged 16-20 weeks and noted that the expression levels of PCNA and Bcl-2 were age related. This illustrates that the proliferation level and anti-apoptotic ability might decrease with increasing fetal age, although the sample number and observation time points in this study were limited. Whether or not this phenomenon is associated with arterial duct occlusion after birth is worth additional investigation. Whether the differences among the VSMC from the arterial duct, aorta, or pulmonary artery are caused by the different genesis of these VSMC or environment, biology, or blood flow dynamics requires further investigation using animal experiments.

\section{Acknowledgements}

We would like to thank Ms Xiao-hong GENG and $\mathrm{Mr}$ Jian-bo WU for their help with the embryectomy.

\section{References}

1 Clyman RI, Chan CY, Mauray F, Chen YQ, Cox W, Seidner SR, et al. Permanent anatomic closure of the ductus arteriosus in newborn baboons: the roles of postnatal constriction, hypoxia, and gestation. Pediatr Res 1999; 45: 19-29.

2 Sarkar FH, Rahman KM, Li Y. Bax translocation to mitochondria is an important event in inducing apoptotic cell death by indole-3-carbinol (I3C) treatment of breast cancer cells. J Nutr 2003; 133: 2434S-2439S.

3 Bogoyevitch MA, Court NW. Counting on mitogen-activated protein kinases-ERKs 3, 4, 5, 6, 7 and 8. Cell Signal 2004; 16: 1345-54.

4 Johnson GL, Lapadat R. Mitogen-activated protein kinase pathways mediated by ERK, JNK, and p38 protein kinases. Science 2002; 298 : 1911-2.

5 Pearson G, Robinson F, Beers GT, Xu BE, Karandikar M, Berman $\mathrm{K}$ et al. Mitogen-activated protein (MAP) kinase pathways: regulation and physiological functions. Endocr Rev 2001; 22: 153-83.

6 Xia Z, Dickens M, Raingeaud J, Davis RJ, Greenberg ME. Opposing effects of ERK and JNK-p38 MAP kinases on apoptosis. Science $1995 ; 270: 1326-31$.

7 Wu XZ, Shao GY, Chen SR, Wang XW, Wang ZY. Studies on the relationship between protein kinase $\mathrm{C}$ and differentiation of human promyelocytic leukemia cell induced by retinoic acid. Leuk Res 1989; 13: 869-74.

8 Wu XZ, Lu H, Zhou L, Huang Y, Chen H. Changes of phosphatidylcholine-specific phospholipase $\mathrm{C}$ in hepatocarcinogenesis and in the proliferation and differentiation of rat liver cancer cells. Cell Biol Int 1997; 21: 375-81.

9 Wu XZ, Shi PC, Ping H, Chen Y, Du LN. $N$-all-trans-retinoyl-L-proline inhibits metastatic potential of hepatocellular carcinoma cells. Cell Biol Int 2006; 30: 672-80.

10 Shaul PW. Maternal vitamin A administration and the fetal ductus arteriosus. Pediatr Res 2001; 49: 744-6.

11 Momma K, Toyono M, Miyagawa-Tomita S. Accelerated maturation of fetal ductus arteriosus by maternally administered vitamin A in rats. Pediatr Res 1998; 43: 629-32.

12 Forutan F, Mai JK, Ashwell KW, Lensing-Hohn S, Nohr D, Voss $\mathrm{T}$ et al. Organisation and maturation of the human thalamus as revealed by CD15. J Comp Neurol 2001; 437: 476-95.

13 Teng JY, XU SJ, WU LH. Culture model in vitro of fetal arterial smooth muscle cells and their growth characters. J Hangzhou Med Coll 2004; 25: 53-5.

14 Cory S, Adams JM. Killing cancer cells by flipping the Bcl-2/Bax switch. Cancer Cell 2005; 8: 5-6.

15 Vogel MW. Cell death, Bcl-2, Bax, and the cerebellum. Cerebellum 2002; 1: 277-87.

16 Wan H, Dawson MI, Hong WK, Lotan R. Enhancement of Calu1 human lung carcinoma cell growth in serum-free medium by retinoids: dependence on AP-1 activation, but not on retinoid response element activation. Oncogene 1997; 15: 2109-18.

17 Garcia-Montes JA, Zabal CC, Calderon-Colmenero J, Juanico EA, Cardona GA, Colin Ortiz JL, et al. [Patent ductus arteriosus in the adult: transcatheher treatment immediate and medium term results]. Arch Cardiol Mex 2006; 76: 163-8.

18 Zhu L, Vranckx R, Khau VK, Lalande A, Boisset N, Mathieu F, et al. Mutations in myosin heavy chain 11 cause a syndrome associating thoracic aortic aneurysm/aortic dissection and patent ductus arteriosus. Nat Genet 2006; 38: 343-9.

19 Korsmeyer SJ, Shutter JR, Veis DJ, Merry DE, Oltvai ZN. Bcl-2/ Bax: a rheostat that regulates an anti-oxidant pathway and cell 
death. Semin Cancer Biol 1993; 4: 327-32.

20 Elmazar MM, Ruhl R, Reichert U, Shroot B, Nau H. RAR $\alpha$ mediated teratogenicity in mice is potentiated by an RXR agonist and reduced by an RAR antagonist: dissection of retinoid receptor-induced pathways. Toxicol Appl Pharmacol 1997; 146: 21-8.

21 Yokoyama U, Sato Y, Akaike T, Ishida S, Sawada J, Quan H, et al. Maternal vitamin A alters gene profiles and structural maturation of the rat ductus arteriosus. Physiol Genomics 2007; 31: 13957.

22 Colakoglu N, Kukner A. Teratogenicity of retinoic acid and its effects on TGF- $\beta 2$ expression in the developing cerebral cortex of the rat. J Mol Histol 2004; 35: 823-7.

23 Siu BL, Alonzo MR, Vargo TA, Fenrich AL. Transient dilated cardiomyopathy in a newborn exposed to idarubicin and all-trans- retinoic acid (ATRA) early in the second trimester of pregnancy. Int J Gynecol Cancer 2002; 12: 399-402.

24 Shaul PW. Maternal vitamin A administration and the fetal ductus arteriosus. Pediatr Res 2001; 49: 744-6.

25 Momma K, Toyono M, Miyagawa-Tomita S. Accelerated maturation of fetal ductus arteriosus by maternally administered vitamin A in rats. Pediatr Res 1998; 43: 629-32.

$26 \mathrm{Wu}$ GR, Jing S, Momma K, Nakanishi K. The effect of vitamin A on contraction of the ductus arteriosus in fetal rat. Pediatr Res 2001; 49: 747-54.

27 Colbert MC, Kirby ML, Robbins J. Endogenous retinoic acid signaling colocalizes with advanced expression of the adult smooth muscle myosin heavy chain isoform during development of the ductus arteriosus. Circ Res 1996; 78: 790-8.

\section{Correction}

Cheng LF, Yan D, Turdi S, Kerram P. Biphasic effects of haloperidol on sodium currents in guinea pig ventricular myocytes. Acta Pharmacol Sin 2007 Jun; 28(6): 783-8.

Yan D, Cheng LF, Song HY, Turdi S, Kerram P. Electrophysiological effects of haloperidol on isolated rabbit Purkinje fibers and guinea pigs papillary muscles under normal and simulated ischemia. Acta Pharmacol Sin 2007 Aug; 28(8): 1155-60.

The two papers were co-supported by National Natural Science Foundation of China (№ 30460147) and Scientific Planning Project of Xinjiang High Education (№XJEDU2005I14). 